\section{Performance of the systemic lupus erythematosus disease activity score (SLE-DAS) in a Latin American population.}

The accurate assessment of disease activity in patients with systemic lupus erythematosus (SLE) remains a pending task. Recently, Jesus et al developed and validated a novel instrument, the SLE Disease Activity Score (SLE-DAS), in two representative cohorts of Caucasian patients. ${ }^{1}$ Through an elegant methodology, the authors demonstrated that SLE-DAS provides a more accurate identification of clinically meaningful changes over time, with higher sensitivity and similar specificity compared with the SLE Disease Activity Index 2000 (SLEDAI-2K). Although these finding have adequate methodological support, there are some points of concern that deserve further clarification. On the one hand, a clinimetric instrument must be validated in populations of different ethnic and geographical substrate before being accepted as of generalised use. On the other hand, the extent of lupus activity does not show a linear distribution in patients from a real-life scenario, so the performance of any instrument should be evaluated in individuals with quiescence or mild disease activity separately from patients with moderate to severe disease activity.

In an attempt to answer these unsolved questions, we conducted a study in our lupus cohort, which is based on a general practice of rheumatology in a university setting. ${ }^{2}{ }^{3}$ All of our participants are Mexican Mestizos, a representative subgroup of the Latin American ethnicity that comes mainly from a mixture of Amerindian and European ancestry, as well as a small share of African ancestry. From March to June 2019, all patients with SLE (fulfilling the American College of Rheumatology updated classification criteria) who attended our outpatient rheumatology clinic were studied. ${ }^{4}$ Individuals underwent a thorough clinical examination and an evaluation of the medical records was performed, including concomitant laboratory reports performed in the 5 days prior to the consultation. Once completed, records of each patient were rated for the SLE-DAS and SLEDAI-2K, as established by the respective rule. ${ }^{15}$

A total of 227 patients were studied, whose main characteristics are summarised in table 1.

To evaluate the validity of the SLE-DAS, we compared the SLE-DAS score with the SLEDAI-2K score by correlation analysis. There was a strong positive correlation between instruments throughout the cohort, with a Spearman's rho coefficient of 0.92 (95\% CI 0.90 to $0.94 ; \mathrm{p}<0.0001)$. However, this figure was seriously modified when the analyses were carried out according to the extent of disease activity. Indeed, although the Spearman's rho coefficient was maintained (rho $=0.90,95 \%$ CI 0.87 to 0.93 ; $\mathrm{p}<0.0001$ ) when the correlation was investigated in patients with quiescence or low disease activity (SLEDAI-2K $<6 ; \mathrm{n}=167$ ), it fell dramatically to 0.46 (95\% CI 0.22 to $0.64 ; \mathrm{p}=0.0002)$ when only individuals with moderate to severe disease activity were

\begin{tabular}{lc}
\hline Table 1 & Main characteristics of our lupus cohort $(\mathrm{n}=227)$ \\
\hline Female, $\mathrm{n}(\%)$ & $209(92.1)$ \\
\hline Age in years, mean \pm SD & $42.2 \pm 13.2$ \\
\hline Disease duration in years, mean \pm SD & $9.4 \pm 7.2$ \\
Sjögren's syndrome, $\mathrm{n}(\%)$ & $29(12.8)$ \\
Antiphospholipid syndrome, $\mathrm{n}(\%)$ & $33(14.5)$ \\
Diabetes, $\mathrm{n}(\%)$ & $19(8.4)$ \\
\hline Hypertension, $\mathrm{n}(\%)$ & $53(23.3)$ \\
\hline
\end{tabular}

A
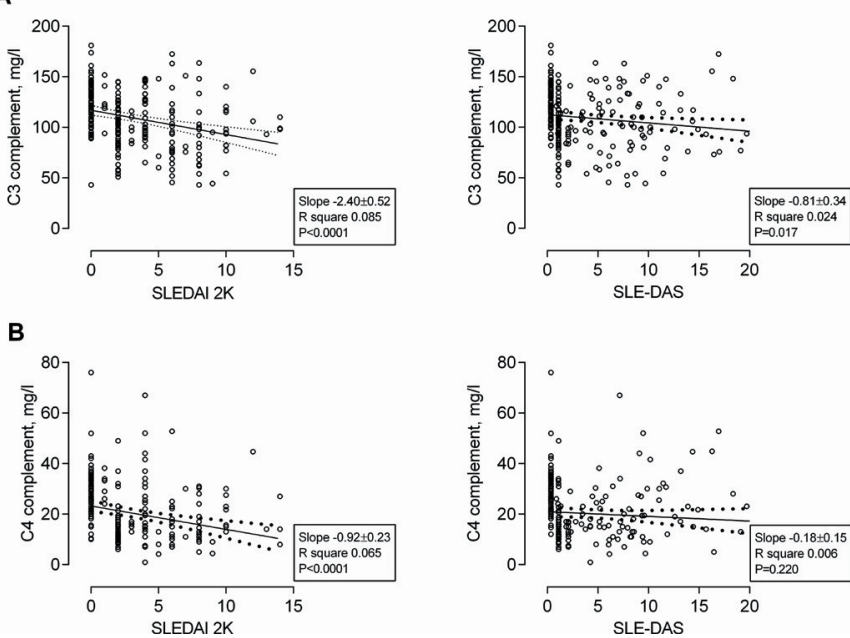

Figure 1 Linear regression analysis showing the existence of significant regression coefficients between $\mathrm{C} 3$ complement levels and both SLEDAI-2K and SLE-DAS scores (A). Conversely, C4 complement levels showed a linear association with SLEDAI-2K score but not with SLE-DAS score (B).SLEDAI-2K, SLE Disease Activity Index 2000.

analysed (SLEDAI-2K $\geq 6 ; n=60$ ). The magnitude of the positive correlation between the overall scores found here is similar to those observed in the derivation cohort (Portuguese, rho $=0.94$; $\mathrm{p}<0.0005$ ) and in the validation cohort (Italians, rho=0.94; $\mathrm{p}<0.0005)$ used for the development of the SLE-DAS score. ${ }^{1}$ However, an analysis recently published in 41 Indian patients suggested that correlation between clinimetric tools depends predominantly on the level of the disease activity. ${ }^{6}$ In this study, although the correlation between scores was moderate (rho $=0.70 ; \mathrm{p}<0.001)$ in patients with active lupus nephritis, it increased significantly after 6 months of successful induction therapy $(r h o=0.92 ; \mathrm{p}<0.001)$.

We perform additional analyzes to deepen our understanding of the clinical performance of each of the scores. Considering that serum complement levels are among the most validated and standardised biomarkers to reflect activity in SLE, we evaluated whether variations in complement levels could be attributed to variations in each clinimetric tool. The results of linear regression analysis are presented in figure 1. As observed, both SLEDAI-2K and SLE-DAS showed low but statistically significant regression coefficients to predict C3 complement levels (figure 1A). However, for the C4 complement levels only the SLEDAI-2K showed a low but evident degree of linear association, whereas the SLE-DAS showed no relationship between variables (figure 1B).

Our results confirm that SLE-DAS has an adequate performance and a high correlation with SLEDAI- $2 \mathrm{~K}$ in the context of quiescent lupus and in patients with low disease activity, although its performance in SLE patients with moderate to severe activity may not be robust. Suboptimal performance of the SLE-DAS in subjects with high disease activity could be due to a 'ceiling effect', at a level above which one or several variables associated with disease activity no longer have a significant additive effect in the SLE-DAS score. Alternatively, it is possible that a part of the strong correlation between SLEDAI-2K and SLE-DAS is due to the accumulation of patients with low disease activity (most of them in clinical quiescence) around the score 0 in both clinimetric tools.

In summary, we validated the SLE-DAS as a useful tool to measure activity in SLE in an independent cohort of Latin American patients with Mexican Mestizo ethnicity. However, our results also suggest that SLE-DAS does not add an advantage 
over the existing SLEDAI-2K score, and its performance in patients with high disease activity seems to be suboptimal.

\section{Melissa G Rodríguez-González, ${ }^{1}$ Grissell A Valero-Gaona, ${ }^{1}$} Tania Vargas-Aguirre, ${ }^{1}$ Luis M Amezcua Guerra $\odot^{2}$

'Departamento de Reumatología, Instituto Nacional de Cardiologia Ignacio Chavez, Mexico City, Mexico

2Departamento de Inmunología, Instituto Nacional de Cardiologia Ignacio Chavez, Mexico City, Mexico

Correspondence to Dr Luis M Amezcua Guerra, Departamento de Inmunología, Instituto Nacional de Cardiologia Ignacio Chavez, Mexico City, MX 14080, Mexico; Imamezcuag@gmail.com

Contributors MGR-G, GAV-G, TV-A and LMAG contributed to the conception and design, acquisition of data, analysis and interpretation of the data and final approval of the manuscript. LMAG drafted the manuscript and all authors critically revised the article for important intellectual content.

Funding The authors have not declared a specific grant for this research from any funding agency in the public, commercial or not-for-profit sectors.

Competing interests None declared.

Patient consent for publication Nor required.

Provenance and peer review Not commissioned; internally peer reviewed.

(c) Author(s) (or their employer(s)) 2020. No commercial re-use. See rights and permissions. Published by BMJ.

\section{A) Check for updates}

To cite Rodríguez-González MG, Valero-Gaona GA, Vargas-Aguirre T, et al. Ann Rheum Dis 2020;79:e158.
Received 15 July 2019

Accepted 18 July 2019

Published Online First 29 July 2019

\section{Linked}

- http://dx.doi.org/10.1136/annrheumdis-2019-216110

Ann Rheum Dis 2020;79:e158. doi:10.1136/annrheumdis-2019-216028

ORCID iD

Luis M Amezcua Guerra http://orcid.org/0000-0002-6258-5732

\section{REFERENCES}

1 Jesus D, Matos A, Henriques C, et al. Derivation and validation of the SLE disease activity score (SLE-DAS): a new SLE continuous measure with high sensitivity for changes in disease activity. Ann Rheum Dis 2019;78:365-71.

2 Hübbe-Tena C, Gallegos-Nava S, Márquez-Velasco R, et al. Pulmonary hypertension in systemic lupus erythematosus: echocardiography-based definitions predict 6-year survival. Rheumatology 2014;53:1256-63.

3 Castillo-Martínez D, Marroquín-Fabián E, Lozada-Navarro AC, et al. Levels of uric acid may predict the future development of pulmonary hypertension in systemic lupus erythematosus: a seven-year follow-up study. Lupus 2016;25:61-6.

4 Hochberg MC. Updating the American College of rheumatology revised criteria for the classification of systemic lupus erythematosus. Arthritis Rheum 1725;1997:40.

5 Gladman DD, Ibañez D, Urowitz MB. Systemic lupus erythematosus disease activity index 2000. J Rheumatol 2002:29:288-91.

6 Mathew A, Chengappa KG, Shah S, et al. SLE-DAS: ready for routine use? Ann Rheum Dis 2020:79:e116. 